EPJ Web of Conferences 45, 01070 (2013)

DOI: $10.1051 /$ epjconf/20134501070

(C) Owned by the authors, published by EDP Sciences, 2013

\title{
Neutrally stratified flow modelling over complex terrain at meso-scale: open-cut coal mine study
}

\author{
S. Nosek ${ }^{1}$, Z. Janour ${ }^{1}$, K. Jurcakova ${ }^{1}$, R. Kellnerova ${ }^{1,2}$, and L. Kukacka ${ }^{1,2}$ \\ ${ }^{1}$ Institute of Thermomechanics AS CR, Prague, Czech Republic \\ ${ }^{2}$ Charles University, Department of Meteorology and Environment Protection, Prague, Czech Republic
}

\begin{abstract}
The objective of this case study was to determine the influence of the coal mine cavity and its vicinity on the main flow field with respect to prevailing wind direction. In order to model the neutrally stratified flow over extremely huge open-cut coal mine Libouš situated at north-west of Czech Republic the laminar flow analogy was applied. The model was scaled down to 1:9000 according to dimensions of windtunnel and selected coal mine surroundings. The measurements of longitudinal and lateral velocity components in selected vertical, resp. horizontal planes were performed by LDA. The measured data will be used for validation of CFD simulation and for selections of area of interest at bigger scales where turbulent flow modelling will be performed. The results revealed that not only of cavity shape and deepness but also the surroundings orography has influence on flow pattern, hence on ventilation, within the area of interest.
\end{abstract}

\section{Introduction}

Open-cut coal mine Libouš situated in north-west of Czech Republic is approx. $5 \mathrm{~km}$ long, $4 \mathrm{~km}$ wide and the biggest depth is around $200 \mathrm{~m}$. The mine is surrounded by Ore Mountains on the north and north-west (see figure 1), by town Chomutov and several villages on north and north-east. From west, south and east side is surrounded within a few kilometres by flat terrain covered by uncutted grass. The shape of mine cavity resembles letter $\mathrm{L}$ lying down. Because of mentioned town and villages situated downstream of the prevailing wind direction (from west) the objective of this study is to understand the transport and dispersion of dust particles from mining processes. For the first approach we decided to determine the main flow field within the coal mine cavity and its downstream vicinity with respect to only one, prevailing, wind direction.

\section{Methods}

\subsection{Theoretical assessment of flow regime}

The basic of the physical modelling of atmospheric flow is to form the boundary layer over the model arranged at wind-tunnel working section. From inspectional analysis is generally concluded that geometric, dynamic, and kinematic similarity must be satisfied. However, all of these requirements cannot be satisfied simultaneously in existing facilities and approximate simulation for particular application has been worked out.

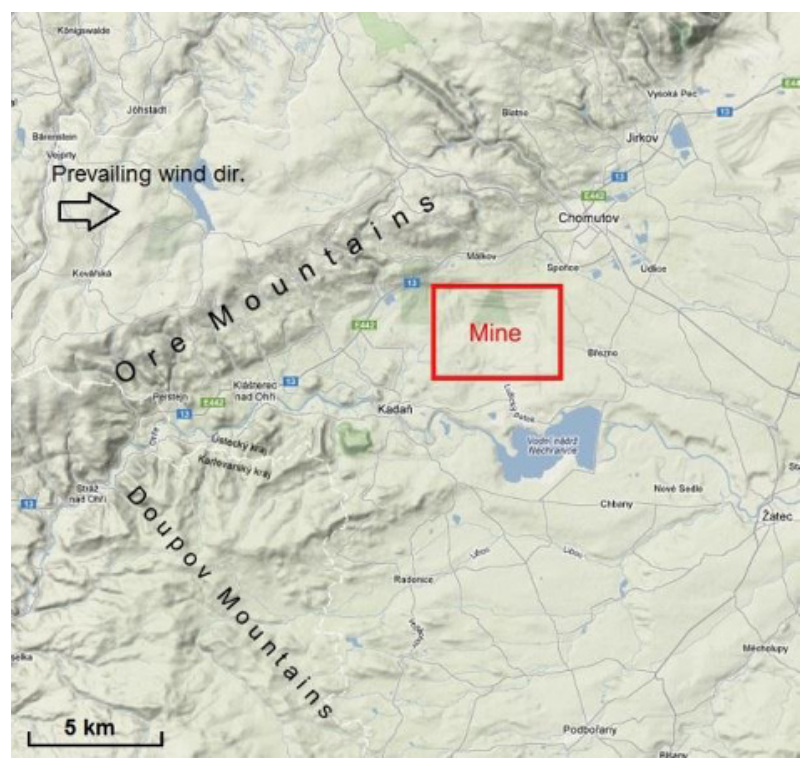

Fig. 1. Terrain map of studied area including characteristic orography. The open-cut coal mine Libouš is marked with red rectangle.

Because of coal mine huge dimensions and surrounding terrain complexity where the characteristic (horizontal) length is bigger than $5 \mathrm{~km}$ the laminar flow analogy has been chosen according to standards [1]. The laminar flow analogy was introduced by Abe [2] where the cloud formation over the peak of Mt. Fuji was modeled at scale 1:50 000 in wind-tunnel (the chamber was $0.8 \mathrm{~m}$ wide, $0.9 \mathrm{~m}$ long and $0.35 \mathrm{~m}$ high). He argued 
that equality of Reynolds numbers can be achieved by replacing kinematic viscosity $v$ in the Reynolds expression in wind-tunnel with eddy diffusivity for momentum at real atmosphere. If $K$ is approximated as a constant

$$
K=10^{4} v,
$$

the following relation

$$
\left(\frac{U L}{v}\right)_{\text {model }}=\left(\frac{U L}{K}\right)_{\mathrm{atm}},
$$

where $U_{\text {model }}$ and $U_{\text {atm }}$ is mean velocity of the flow in model, resp. in real atmosphere, is satisfied if the turbulent atmospheric flow is modeled by laminar flow in wind-tunnel provided by length scale ratio $L_{\mathrm{m}} / L_{\mathrm{atm}}=$ $1 / 10^{4}$.

This dynamic similarity was widely used by Cermak [3] at special boundary-layer wind tunnel at Colorado State University where stable stratified flow and scale ratios from 1:5000 to 1:50000 were performed. As reported in [4] at such scales many of the similarity conditions normally applied to the simulation of flow over complex terrain cannot be satisfied. Nevertheless, acceptable agreement between laboratory and field measurements is reported.

In case of neutrally stratified flow modeling Janour [5] conducted laminar flow analogy on 1:6000 scale model comprising Czech town Př́bram with its surrounding landscape. The twenty-four hours and the year mean surface concentrations field for year 1975 and 1993 were assessed in studied area.

\subsection{Experimental setup}

\subsubsection{Wind tunnel}

The experiment was performed at open Environmental wind-tunnel of Institute of Thermomechanics Academy of Sciences of the Czech Republic in Nový Knín. The wind-tunnel test section is $1.5 \mathrm{~m}$ wide, 1.5 high and $2 \mathrm{~m}$ long. The length of section for appropriate laminar boundary layer development (smooth section) was set to $18 \mathrm{~m}$. The flow speed in wind-tunnel was maintained at $0.25 \mathrm{~m} / \mathrm{s}$ with error $6 \%$.

\subsubsection{Model}

Selection of appropriate area embodying influence on flow over coal mine Libouš was a difficult task for model design. Due to laminar flow analogy the model scale was downed to $1: 9000(1.5 \times 1.5 \mathrm{~m})$. This resulted in complex area comprising Ore Mountains and large coal mine vicinity (figure 2).

The model was made of extruded PVC and manufactured by computer numerically controlled (CNC) machine with precision of $0.5 \mathrm{~mm}$. Thus, together with paints the very smooth surface was provided. For CNC input data the geographic information system (GIS) was used [6].

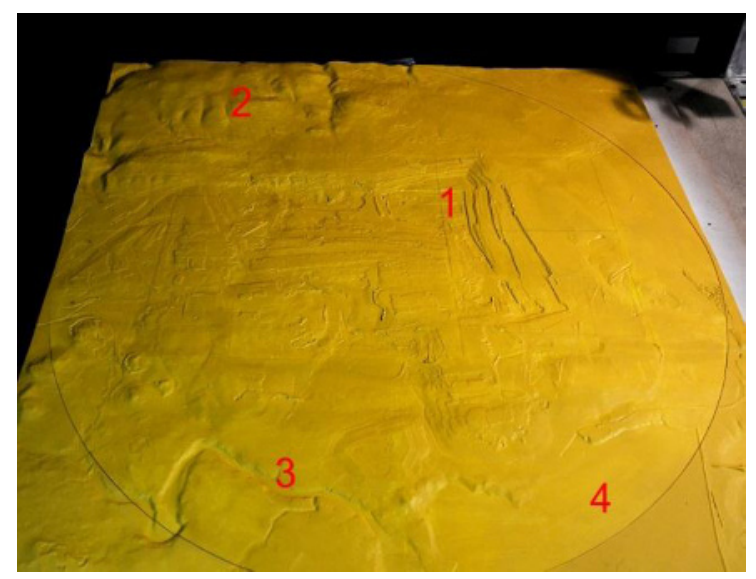

Fig. 2. Model situated in wind-tunnel comprising open-cut coal mine (1), Ore Mountains (2) and river Ohře (3) with dam Nechranice (4). The direction of flow is from left to right (west direction of wind in real atmosphere).

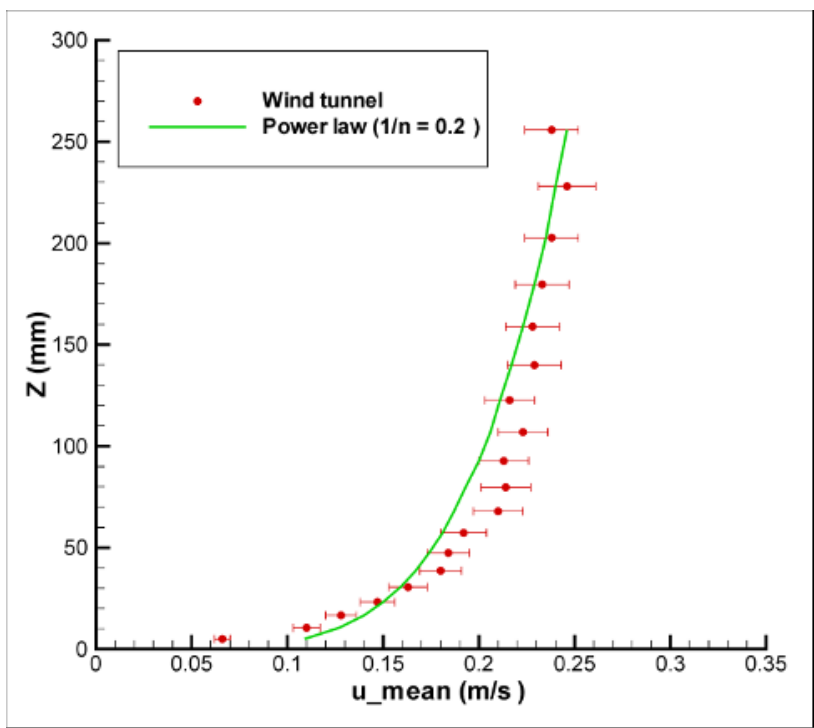

Fig. 3. Measured vertical profile of mean longitudinal velocity at entrance of the model (dots with error bars) and power law profile with exponent $\mathrm{n}=4.8$ (solid line) for $U=0.25 \mathrm{~m} / \mathrm{s}$.

In order to ensure smooth connection between floor of smooth section and the model a special tilt was attached accordingly to model windward relief and stretched to the smooth section floor.

\subsubsection{Measurement techniques}

The flow velocity components (longitudinal, lateral and vertical) were measured via two-dimensional optical fibre Laser Doppler Anemometry (LDA) based on DANTEC BSA F-60 burst processor. Tracing particles were produced by a commercial fog generator SAFEX F2001 and as a fog fluid the SAFEX STANDARD was used. The entrance of tracing particles was at the beginning of wind-tunnel smooth section providing their even distribution in test section. Data rate reached around 600 $\mathrm{Hz}$, resp. $2 \mathrm{kHz}$ at the lowest, resp. the highest measured high above the model. The average data rate was about 1 $\mathrm{kHz}$. The time of recoding was $30 \mathrm{~s}$ in all cases. 


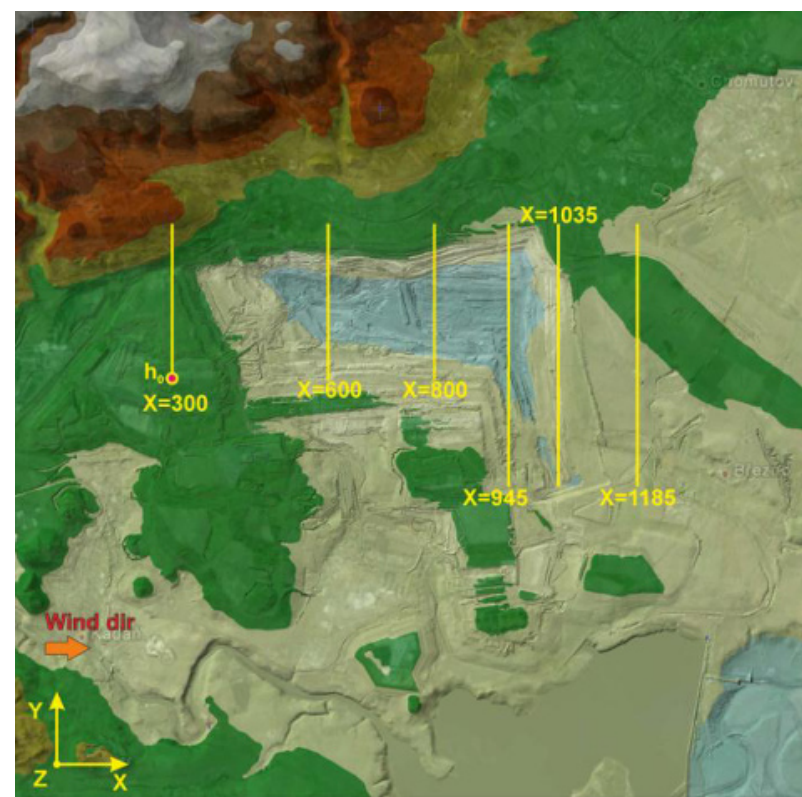

Fig. 4. Measured vertical planes $y z$ (marked vert. lines) at 6 distances of $x$ direction displayed on the model contour map. The origin of coordinate system is at left-bottom corner. The wind direction marked with arrow and coordinates of the model are on the left. Position of reference zero height $h_{0}$ is marked with circle at the plane $x=300$.

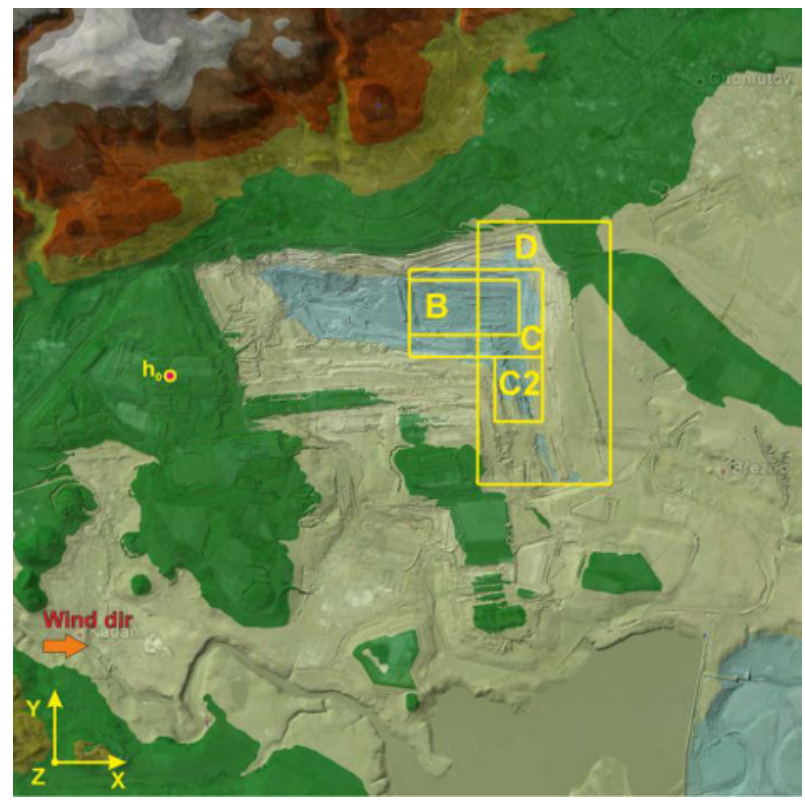

Fig. 5. Measured horizontal planes $x y$ (marked rectangles) on the model contour map: $B, C, C 2$ and $D$. Position of reference zero height $h_{0}$ remains the same as in previous case.

\subsubsection{Boundary layer characteristics}

In figure 3 the measured vertical profile of mean longitudinal velocity $u_{\text {mean }}$ at entrance of the model (above the connecting tilt) for speed in wind tunnel $U=$ $0.3 \mathrm{~m} / \mathrm{s}$ is depicted. From fitting of power law (green curve in figure 3 ) the exponent $1 / \mathrm{n}=0.2$ was obtained. As a characteristic length was set the distance between the highest and lowest point on model $h=70 \mathrm{~mm}$ for which the $R e \approx 1200$ corresponds to laminar flow.

\section{Results}

For measuring of longitudinal velocity component $u$ the characteristic vertical planes $y z$ across the whole mine were selected (figure 4). This resulted in 6 distances at $x$ direction (in mm): $x=300$ (before mine), $x=800$ (1/3 of mine), $x=800$ ( $2 / 3$ of mine), $x=945$ (the deepest mine area), $x=1035$ (end of mine) and $x=1185$ (behind mine). The planes bottom line copy the surface of the model. The lowest measured point was $4 \mathrm{~mm}$ above the model surface.

For lateral velocity component $v$ the 4 horizontal planes $x y$ (figure 5) above last part of the mine were selected at nondimensional heights $z / h$, where $z$ is the height above the model surface with respect to selected plane and reference model zero height $h_{0}: z / h=-0.09(B$, the deepest mine area), $z / h=-0.03(C$ and $C 2), z / h=0.07$ (D).

Graphs of nondimensional velocity component $u / U_{\text {ref }}$ at planes $y z$ are presented in figure 6 . Values $u / U_{\text {ref }}$ were computer from

$$
u / U_{\text {ref }}=\frac{u}{U_{\text {ref }}} \frac{U_{\text {id }}}{U_{\text {ref,mean }}},
$$

Where $u$ is measured mean longitudinal velocity component, $U_{\text {ref }}$ is reference velocity measured at $h_{\text {ref }}=$ $2 h, U_{\text {id }}=0.25 \mathrm{~m} / \mathrm{s}$ is idealized flow velocity in windtunnel and $U_{\text {ref,mean }}$ is mean reference velocity. Thus, undesirable wind-tunnel flow fluctuations are supressed.

From the graphs in figure 6 (viewed from upstream) can be seen deceleration, resp. acceleration of the flow speed within the cavities of the mine, resp. before the top of hills, crests or mine slopes. Before the mine $(x=300$ $\mathrm{mm}$ ) velocity profiles in vertical direction are approx. same along $y$ axis. Disruption of this pattern is evident across the whole mine $(x=600,800,945 \mathrm{~mm})$. The biggest thickness of layer $\delta_{0.25}$, where the flow speed deceleration can be observed $\left(\delta_{0.25}=z / h\right.$, where $u / U_{\text {ref }}<$ $0.25)$, is at $1 / 3(x=600)$ and $2 / 3(x=800)$ of the mine, namely $\delta_{0.25}=0.2$. This is due to deep cavity regions occurring at selected cross-sections (mainly due to high ridge occurring just in the middle of the mine). The $\delta_{0.25}$ is smaller at the deepest mine area $\left(x=945, \delta_{0.25}=0.1\right)$ because this area is followed by mine slope where the flow is accelerated. At this cross-section $(x=1035) \delta_{0.25}$ $=0.05$. Behind the end of mine $(x=1185)$ the vertical velocity profiles are rearranged evenly as before the mine $(x=300)$ with exception that $\delta_{0.25}$ is approx. two times smaller.

In figure 7 there are presented mean lateral velocity components $v_{\text {mean }}$ measured at horizontal planes $x y$. Positive values represents left direction (in sense of wind direction), negative right.

Plane B is the lowest positioned, just above the deepest mine area $(z / h=-0.09)$. Except of small area on the right (where actually begins mine slope) the $v$ component has neutral direction diversion (close to 0 $\mathrm{m} / \mathrm{s}$ ). In the small areas some diversion directions to left can be seen.

Plane $\mathrm{C}$ is positioned higher $(z / h=-0.03)$ and hence can cover bigger area above the deepest mine area. There 

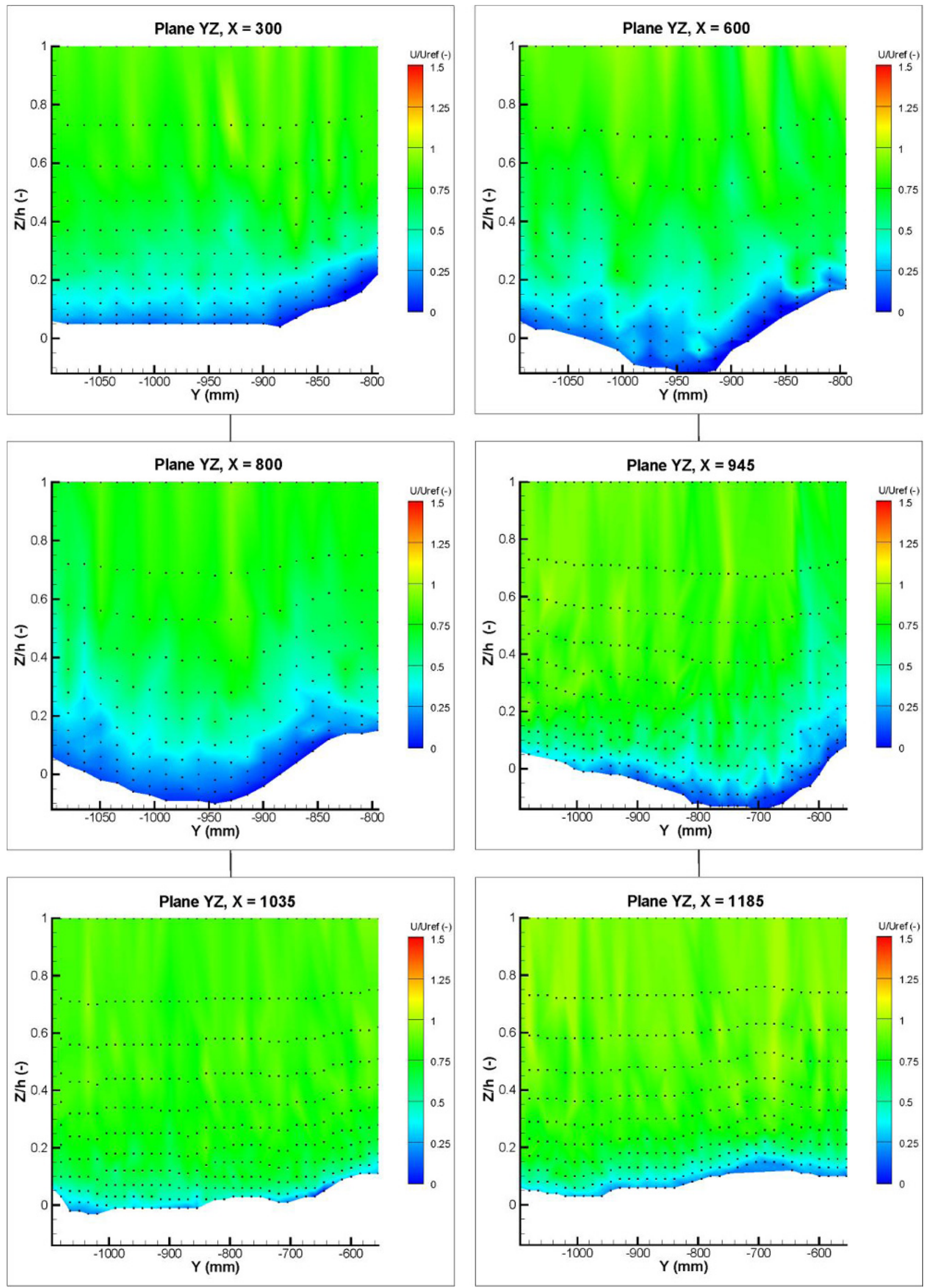

Fig. 6. Graphs of nondimensional longitudinal velocity component $u / U_{\text {ref }}$ at vertical planes $y z$. 

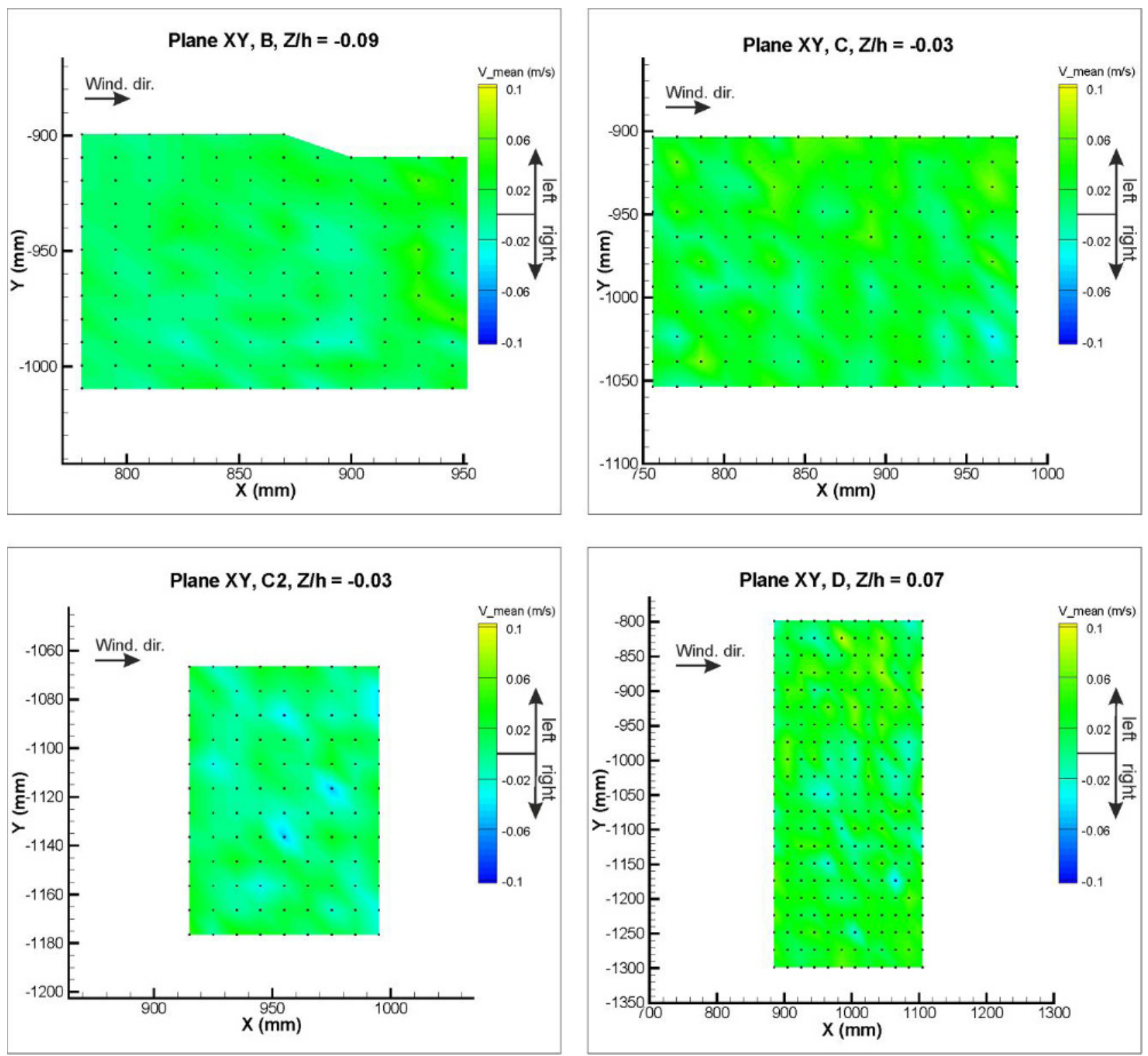

Fig. 7. Graphs of mean lateral velocity component $v_{\text {mean }}$ at vertical planes $y z$.

are many diversions to left in the upper part of the graph and to the right in the lower part of the graph (viewed from the wind direction). However, from the evenly unfolded contours can be concluded that main flow direction is neutral.

Plan C2 is at the same height as C. It demonstrates the influence of the cavity shape which reminds letter L lying down. In this region are many areas where the direction of the flow is mainly diverted little bit to the right.

Plane D cover the broadness of mine at its end. It is positioned just above the outer borders at $z / h=0.07$, thus not so high above the mine surroundings. There is significant diversion of the flow direction to the left in the upper part of the graph. It shows the influence of mine ascent in this area having the corner shape pointed to north-east. In case of middle and right part of the graph the direction diversion of the flow is predominantly neutral, with some areas where the diversion to the right can be observed. It's mainly due to broad gentle ascent oriented to east and south at these areas.
It is necessary to point out that the magnitudes o lateral velocity component are of order $0.01 \mathrm{~m} / \mathrm{s}$. Thus, the analysis of flow direction has only qualitative meaning.

\section{Discussion and conclusion}

Simulation of atmospheric motions above the complex terrain at meso-scale (scale of the model 1:9000) was presented in this paper. For this case, Reynolds number differences are so large that similarity in the ordinary sense does not match the criteria. Thus laminar analogy, where the laminar flow structure dominates by the surface geometry, was applied for this case. Such a flow is observed to be approximately similar in mean velocity to the turbulent prototype flow. The similarity is a result of the turbulent atmosphere behaving roughly as a highly viscous fluid when observed on a scale many times bigger than integral scale of turbulence.

The main objective was to determine the main flow pattern within the cavity of open-cut coal mine Libouš 
and its vicinity. Deceleration of the flow speed was observed in mine cavities. The highest deceleration, thus the worst ventilation, was observed at $1 / 3$ and $2 / 3$ part of the mine, where the deep cavities are presented. The flow acceleration was observed at the end of the mine as well as behind the mine where slopes are presented.

The measurements of lateral velocity component show that the cavity shape (in case of mine end) has influence on flow direction.

\section{Acknowledgments}

Authors acknowledge financial support of project TA01020428 of Technology Agency of the Czech Republic. Author also would like to thanks to Environmental Wind Tunnel Laboratory working group in Nový Knín, Czech Republic.

\section{References}

1. W. H. Snyder, Guidelines for fluid modelling of atmospheric diffusion (EPA office of Air Quality, planning and standards, Research Triangle Park, USA, EPA-600/8-81-009, 1981)

2. M. Abe, Bull. Cent. Meteorol. Obs., Pt II, Tokyo, 7, no. 3 (2008)

3. J. E., Cermak, B. L. Meteorol., 30, 261-292 (1984)

4. A. Robins, JWEIA, 91, 1777-1790 (2003)

5. Z. Janour, PHYSMOD 2001: Int. Workshop on physical modelling of flow and dispersion phenomena, Hamburg, (2001)

6. L. Matejicek, Sensors, 8, 3830-3847 (2008) 